http://dx.doi.org/10.5800/GT-2013-4-2-0097

\title{
GEOMAGNETIC CONJUGACY OF MODERN TECTONIC STRUCTURES
}

\author{
G. Ya. Khachikyan ${ }^{1}$, N. S. Zhakupov², N. Zh. Kadyrkhanova ${ }^{2}$ \\ ${ }^{1}$ LLC Institute of Ionosphere, JSC National Center for Space Research and Technology \\ of the National Space Agency of Kazakhstan, Almaty, Republic of Kazakhstan \\ ${ }^{2}$ LLC Institute of Seismology JSC National Science and Technology Holding PARASAT \\ Ministry of Education and Science of Kazakhstan, Almaty, Republic of Kazakhstan
}

\begin{abstract}
An earthquake is an element of the global electric circuit (GEC) - this new idea suggested in the space age is tested in our study. In the frame of the GEC concept, one may expect that tectonic structures of the northern and southern hemispheres may be magnetically conjugated. It is found that the midocean ridges of the southern hemisphere, located along the boundary of the Antarctic lithosphere plate, are magnetically conjugated with the areas of the junction of continental orogens and platforms in the northern hemisphere. The closest geomagnetic conjugacy exists between the southern boundary of Nazca lithospheric plate and the northern boundaries of Cocos and Caribbean lithospheric plates.
\end{abstract}

Key words: tectonic structures, geomagnetic conjugacy.

Recommended by S.I. Sherman

Citation: Khachikyan G.Ya., Zhakupov N.S., Kadyrkhanova N.Zh. 2013. Geomagnetic conjugacy of modern tectonic structures. Geodynamics \& Tectonophysics 4 (2), 187-195. doi:10.5800/GT-2013-4-2-0097.

\section{ГЕОМАГНИТНАЯ СОПРЯЖЕННОСТЬ СОВРЕМЕННЫХ ТЕКТОНИЧЕСКИХ СТРУКТУР}

\section{Г. Я. Хачикян ${ }^{1}$, Н. С. Жакупов ${ }^{2}$, Н. Ж. Кадырханова ${ }^{2}$}

${ }^{1}$ ДТОО Институт ионосферы АО «Национальный центр космических исследований и технологий» Национального космического агентства Республики Казахстан, Алматы, Республика Казахстан ${ }^{2}$ ТОО Институт сейсмологии АО «Национальный Научно-Технологический Холдинг “ПАРАСАТ” ” Министерства образования и науки Республики Казахстан, Алматы, Республика Казахстан

\begin{abstract}
Аннотация: Проведено тестирование новой идеи, рожденной в эру космических исследований, что землетрясение является элементом глобальной электрической цепи, в рамках которой можно ожидать, что тектонические структуры в северном и южном полушариях Земли могут быть магнитосопряженными. Выявлено, что срединно-океанические хребты южного полушария, расположенные вдоль границы Антарктической литосферной плиты, магнитно сопряжены с зонами сочленения орогенных и платформенных структур в северном полушарии. Наиболее выраженная геомагнитная сопряженность наблюдается между южной границей литосферной плиты Нацка и северной границей литосферных плит Кокос и Карибская.
\end{abstract}

Ключевые слова: тектонические структуры, геомагнитная сопряженность. 


\section{1. ВВЕДЕНИЕ}

Эрой космических исследований внесен существенный вклад в развитие наук о Земле и, в частности, задокументированы факты появления электромагнитных и плазменных возмущений в характеристиках околоземного космического пространства (ОКП) накануне ощутимых землетрясений [Afonin et al., 1999; Pulinets, Boyarchuk, 2004]. При этом обнаружено, что электромагнитные и плазменные эффекты, сопутствующие процессу подготовки землетрясения, появляются не только над районом будущего эпицентра, но и в магнитосопряженном районе в противоположном полушарии Земли [Pulinets et al., 2007; Ruzhin et al., 1998]. На основании экспериментальных фактов сформировалось мнение, что в период подготовки землетрясения происходит возмущение электромагнитного и плазменного состояния среды вдоль всей протяженности магнитной силовой трубки, погруженной в зону подготовки очага [Pulinets, Boyarchuk, 2004]. В процессе объяснения этих экспериментальных фактов была выдвинута идея [Pulinets, 2009], что возмущение характеристик ОКП накануне сейсмических событий обусловлено модификацией электрического поля в глобальной электрической цепи (ГЭЦ) электромагнитными возмущениями в литосфере, сопутствующими процессу подготовки землетрясения. Классическая концепция ГЭЦ, предложенная первоначально в работе [Wilson, 1921], представляет собой систему стационарных токов, которая создается проводящими слоями ионосферы и земной коры, с грозовыми генераторами (суммой всех молний вокруг земного шара) в качестве основных источников электродвижущих сил и невозмущенными областями свободной атмосферы в качестве зон возвратных токов [Bering et al., 1998]. Грозовая деятельность планеты обеспечивает разность потенциалов между землей и ионосферой в пределах 200$600 \mathrm{kB}$, общий ток в такой цепи достигает $\sim 2000 \mathrm{~A}$, а глобальное электрическое сопротивление составляет 230 Ом [National Research..., 1986]. Идея электрической связи между ионосферой и районом подготовки очага землетрясения была недавно успешно использована в работе [Harrison et al., 2010] для объяснения понижения интенсивности естественного ультранизкочастотного радиоизлучения, зарегистрированного спутником DEMETER в ночные часы в верхней ионосфере накануне коровых землетрясений с магнитудой 5.0 и выше [Němec et al., 2009]. В настоящее время ГЭЦ рассматривают также в качестве одного из основных претендентов на механизм солнечно-земных связей, который еще далеко не разработан. Полагают, что верхняя граница ГЭЦ располагается на высоте магнитопаузы, состояние которой модулируется энергией солнечного ветра, и эти модуляции через последовательную цепочку физических процессов влияют на состояние нижележащих геосфер [Rycroft et al., 2000; Harrison, 2004; Makarova, Shirochkov, 1998]. По опре- делению, возмущения на одном участке электрической цепи должны передаваться на все другие ее участки, поэтому в рамках концепции ГЭЦ можно ожидать, что не только верхние участки цепи (ионосфера, магнитосфера, радиационный пояс) могут откликаться на электромагнитные возмущения внизу, где идет процесс подготовки землетрясения [Pulinets, 2009; Harrison et $a l ., 2010]$, но и нижний участок ГЭЦ (твердая земля) также может откликаться на возмущения вверху, включая магнитопаузу. Электрические возмущения на высотах магнитопаузы могут распространяться в нижележащие слои вдоль магнитных силовых линий (продольные токи) [Ohtani et al., 2000], а так как каждая силовая линия погружена в литосферу в двух магнитосопряженных точках, структурные изменения последней, если они связаны с воздействием «сверху», могут быть магнитосопряженными. В данной работе предпринята попытка проверить это предположение. Результаты показали, что между некоторыми современными геолого-тектоническими структурами действительно наблюдается геомагнитная сопряженность.

\section{2. ДАННЫЕ И МЕТОД АНАЛИЗА}

В южном полушарии одной из важных геологотектонических структур являются срединно-океанические хребты, расположенные вдоль границы Антарктической литосферной плиты. В связи с этим, на основе карты, представленной на сайте (http://www.maps. nationalgeographic.com), с использованием технологии ГИС были определены координаты 38 точек, распределенных достаточно равномерно вдоль границы Антарктической литосферной плиты. Затем были рассчитаны координаты магнитосопряженных точек и определены номера магнитных силовых линий $(L)$, соединяющих магнитосопряженные точки. Номер магнитной силовой линии определяется соотношением: $L=\mathrm{R} / \mathrm{R} 3$, где $\mathrm{R}$ - расстояние от центра геомагнитного диполя до точки данной линии над геомагнитным экватором, а R3 - радиус Земли. Для расчета координат магнитосопряженных точек и значений $L$ была использована международная справочная модель геомагнитного поля (IGRF) (http://www.ngdc.noaa.gov/IAGA/ vmod/igrf.html) и компьютерные коды программы GEOPACK [Tsyganenko, 2008].

Модель IGRF представляет главное магнитное поле Земли, обусловленное внутренними источниками, через отрицательный градиент скалярного потенциала $V$, который, в свою очередь, представлен усеченным рядом сферических гармоник $N$ в виде :

$$
\begin{aligned}
& V(r, Q, \lambda, t)= \\
& =R \sum_{n=1}^{N} \sum_{m=1}^{n}\left(\frac{R}{r}\right) \cdot\left(g_{n}^{m}(t) \cos m \lambda+h_{n}^{m}(t) \sin m \lambda\right) \cdot P_{n}^{m}(Q),
\end{aligned}
$$

где $r$ - расстояние до центра Земли; $Q$ - коширота 
Географические координаты для 38 точек, выбранных вдоль границы Антарктической литосферной плиты; координаты их магнитосопряженных точек и номера геомагнитных силовых линий, соединяющих эти точки для эпохи 2000 г.

Geographic coordinates for 38 sites chosen along the boundary of the Antarctic lithosphere plate; coordinates of their magnetically conjugated sites; numbers of geomagnetic field lines connecting these sites in the year of 2000

\begin{tabular}{|c|c|c|c|c|c|}
\hline № & $\begin{array}{l}\text { Широта точки в } \\
\text { южном полушарии } \\
\text { (град.) }\end{array}$ & $\begin{array}{l}\text { Долгота точки в } \\
\text { южном полушарии } \\
\text { (град.) }\end{array}$ & $\begin{array}{l}\text { Широта магнитосопряженной } \\
\text { точки в северном полушарии } \\
\text { (град.) }\end{array}$ & $\begin{array}{l}\text { Долгота магнитосопряженной } \\
\text { точки в северном полушарии } \\
\text { (град.) }\end{array}$ & $\begin{array}{l}\text { Номер магнитной } \\
\text { силовой линии }\left(\mathrm{R}_{\mathrm{E}}\right)\end{array}$ \\
\hline 1 & -60.62 & -26.74 & 44.89 & -51.89 & 2.52 \\
\hline 2 & -58.53 & -11.84 & 48.73 & -41.44 & 2.68 \\
\hline 3 & -54.93 & -0.63 & 50.96 & -30.48 & 2.67 \\
\hline 4 & -52.15 & -12.79 & 45.77 & -39.83 & 2.27 \\
\hline 5 & -52.77 & -26.95 & 40.35 & -50.77 & 2.04 \\
\hline 6 & -46.17 & -33.62 & 33.52 & -54.28 & 1.67 \\
\hline 7 & -43.59 & -39.11 & 29.08 & -57.33 & 1.52 \\
\hline 8 & -37.79 & -50.27 & 19.01 & -62.54 & 1.28 \\
\hline 9 & -33.63 & 56.39 & 47.44 & 46.19 & 1.89 \\
\hline 10 & -28.91 & 62.08 & 43.5 & 54.42 & 1.66 \\
\hline 11 & -25.61 & 69.98 & 40.93 & 63.73 & 1.54 \\
\hline 12 & -30.01 & 75.81 & 45.7 & 68.07 & 1.78 \\
\hline 13 & -35.34 & 79.08 & 51.17 & 69.05 & 2.16 \\
\hline 14 & -40.94 & 85.98 & 57.39 & 73.7 & 2.84 \\
\hline 15 & -43.68 & 94.86 & 61.12 & 83.04 & 3.46 \\
\hline 16 & -48.08 & 101.95 & 66.44 & 88.63 & 5.04 \\
\hline 17 & -49.83 & 110.91 & 68.98 & 99.54 & 6.27 \\
\hline 18 & -49.63 & 120.69 & 69.11 & 117.92 & 6.01 \\
\hline 19 & -50.47 & 131.11 & 69.68 & 136.38 & 6.06 \\
\hline 20 & -50.45 & 138.96 & 68.86 & 152.02 & 5.57 \\
\hline 21 & -54.89 & 146.8 & 71.17 & 172.89 & 7.54 \\
\hline 22 & -60.76 & 150.46 & 73.29 & -167.11 & 9.86 \\
\hline 23 & -61.76 & 160.99 & 69.09 & -143.65 & 9.46 \\
\hline 24 & -64.64 & 172.45 & 65.1 & -123.97 & 9.53 \\
\hline 25 & -63.43 & -167.82 & 58.31 & -117.41 & 6.55 \\
\hline 26 & -63.26 & -158.66 & 55.17 & -113.23 & 5.32 \\
\hline 27 & -59.85 & -151.66 & 50.71 & -113.85 & 3.75 \\
\hline 28 & -57.34 & -140.47 & 45.15 & -109.41 & 2.87 \\
\hline 29 & -55.87 & -127.98 & 40.02 & -102.69 & 2.39 \\
\hline 30 & -53.30 & -119.27 & 35.37 & -98.67 & 2.03 \\
\hline 31 & -48.79 & -113.24 & 29.98 & -96.81 & 1.71 \\
\hline 32 & -42.51 & -112.89 & 24.89 & -99.14 & 1.47 \\
\hline 33 & -34.26 & -112.82 & 18.42 & -102.44 & 1.26 \\
\hline 34 & -35.79 & -105.7 & 17.28 & -95.16 & 1.26 \\
\hline 35 & -37.03 & -97.3 & 15.65 & -89.51 & 1.25 \\
\hline 36 & -41.60 & -89.36 & 17.64 & -83.31 & 1.31 \\
\hline 37 & -42.49 & -82.16 & 17.35 & -78.99 & 1.31 \\
\hline 38 & -46.26 & -76.33 & 20.66 & -75.7 & 1.4 \\
\hline
\end{tabular}

(90 - широта); $\lambda$ - долгота; $R$ - радиус Земли, равный 6371.2 км; $g_{n}{ }^{m}$ и $h_{n}{ }^{m}-$ коэффициенты Гаусса, зависящие от времени $t ; P_{n}{ }^{m}(Q)$ - присоединенные функции Лежандра степени $n$, порядка $m$. Модель IGRF имеет ошибку из-за ошибки в значениях численных коэффициентов, что связано с пространственной ограниченностью экспериментальных данных, использованных для расчета коэффициентов. В течение двух лет, 19791980 гг., когда измерения геомагнитного поля производились на спутнике MAGSAT, и после 1999 г., когда поступали регулярные данные со спутников Ørsted и СНАМР, измерениями охвачены практически все регионы планеты. Начиная с 70-х годов XX в. модель IGRF воспроизводит значения характеристик главного магнитного поля с достаточно высокой степенью точ- ности. Согласно оценкам рабочей группы по созданию модели (http://www.ngdc.noaa.gov/IAGA/vmod/igrf.html), среднеквадратическая ошибка определения модуля полного вектора главного магнитного поля для настоящего времени находится в пределах 10 нТл. При среднеквадратической ошибке для модуля в 10 нТл среднеквадратические ошибки для северной, восточной и вертикальной компонент геомагнитного поля будут составлять порядка 5-7 нТл. Что же касается реально наблюдаемого поля в конкретном географическом районе, которое включает как главное поле, генерируемое токами в жидком ядре Земли, так и поле, обусловленное намагниченностью горных пород в земной коре, то здесь среднеквадратическая ошибка модели IGRF составляет порядка 200 нТл. В данной 


\section{The Earth's Fractured Surface}

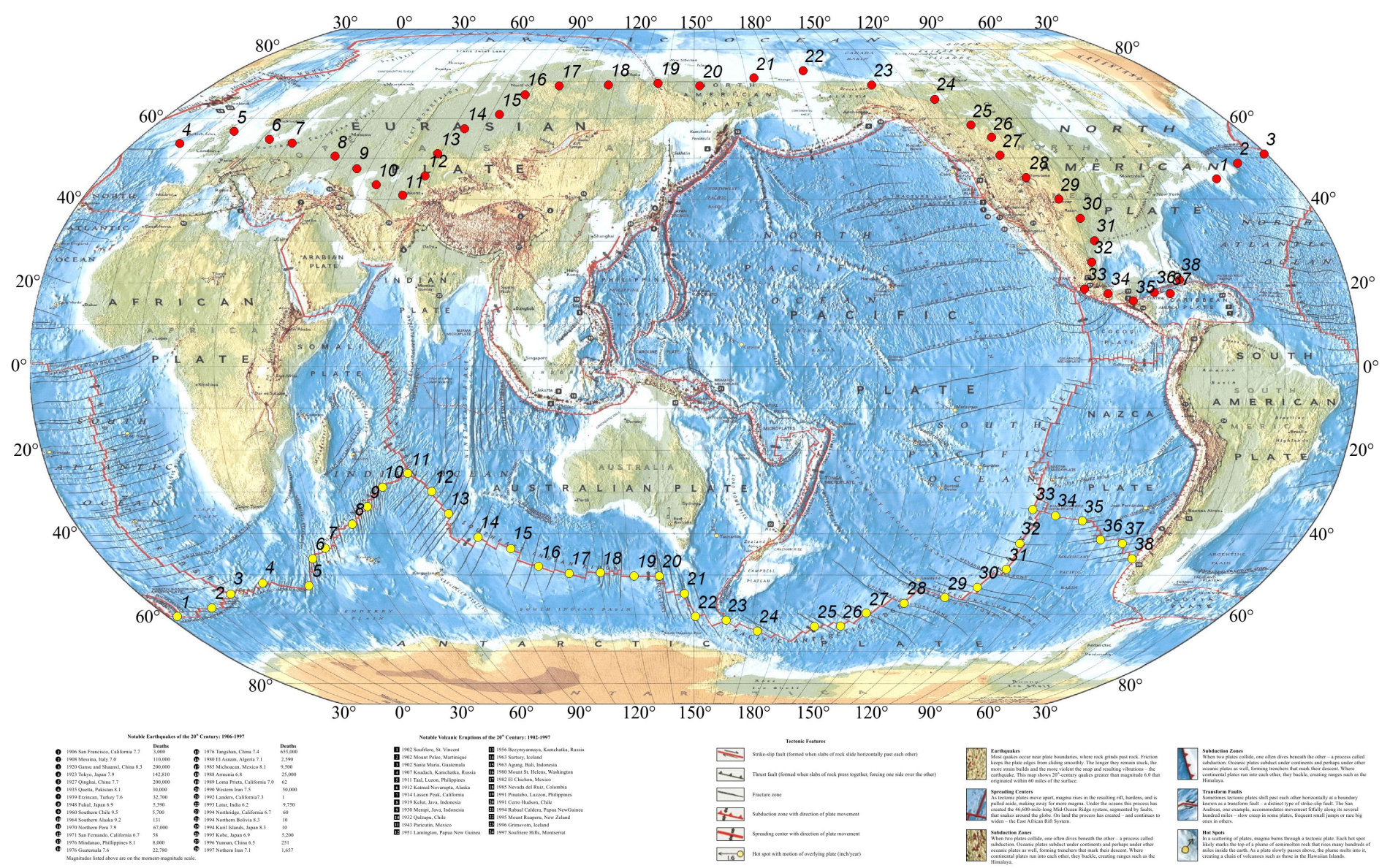

Рис. 1. Расположение 38 точек в южном полушарии вдоль границы Антарктической литосферной плиты (желтые круги с соответствующими цифрами) и магнитосопряженные с ними точки в северном полушарии (красные круги с соответствующими номерами), рассчитанные для геомагнитных условий 2000 г.

Fig. 1. Locations of 38 sites in the southern hemisphere along the boundary of the Antarctic lithosphere plate (yellow circles with corresponding numbers) and magnetically conjugated sites in the northern hemisphere (red circles with corresponding numbers) calculated for geomagnetic conditions of 2000.

работе расчеты параметров главного поля выполнены для магнитной ситуации 2000 г. Значения исходных и рассчитанных параметров приведены в таблице.

\section{3. РЕЗУЛЬТАТЫ}

На рис. 1 показано расположение 38 точек, выбранных в южном полушарии вдоль границы Антарктической литосферной плиты (желтые круги с соответствующими номерами) и магнитосопряженные с ними точки в северном полушарии (красные круги с соответствующими номерами). Магнитные силовые линии, соединяющие магнитосопряженные точки, представлены на рис. 2. На рис. 1, 2 показано, что граница Антарктической литосферной плиты находится в магнитной сопряженности с зоной сочленения орогенных и платформенных структур в северном полушарии. Наиболее четко это проявляется для геолого-тектониче- ских структур, расположенных в американском долготном секторе. Так, на рис. 3 представлен фрагмент глобальной цифровой карты тектонической активности Земли (Digital Tectonic Activity Map (DTAM-1)), на которую нанесены исходные и магнитосопряженные точки с номерами 22-38 (желтые круги). Рис. 2 убедительно демонстрирует «геомагнитную связь» между частью спрединговой границы Антарктической литосферной плиты в южном полушарии и разломами в зоне сочленения Кордильер с Северо-Американской платформой в северном полушарии.

Рисунки 1-3 показывают также, что тесная магнитная сопряженность имеет место между южной границей литосферной плиты Нацка и северными границами плит Кокос и Карибская. Поскольку границы литосферных плит маркируются эпицентрами землетрясений, мы представили на рис. 4 черными крестиками эпицентры землетрясений с магнитудой $\mathrm{M} \geq 5.0$, зарегистрированных в 1973-2010 гг. (каталог NEIC (http:// 


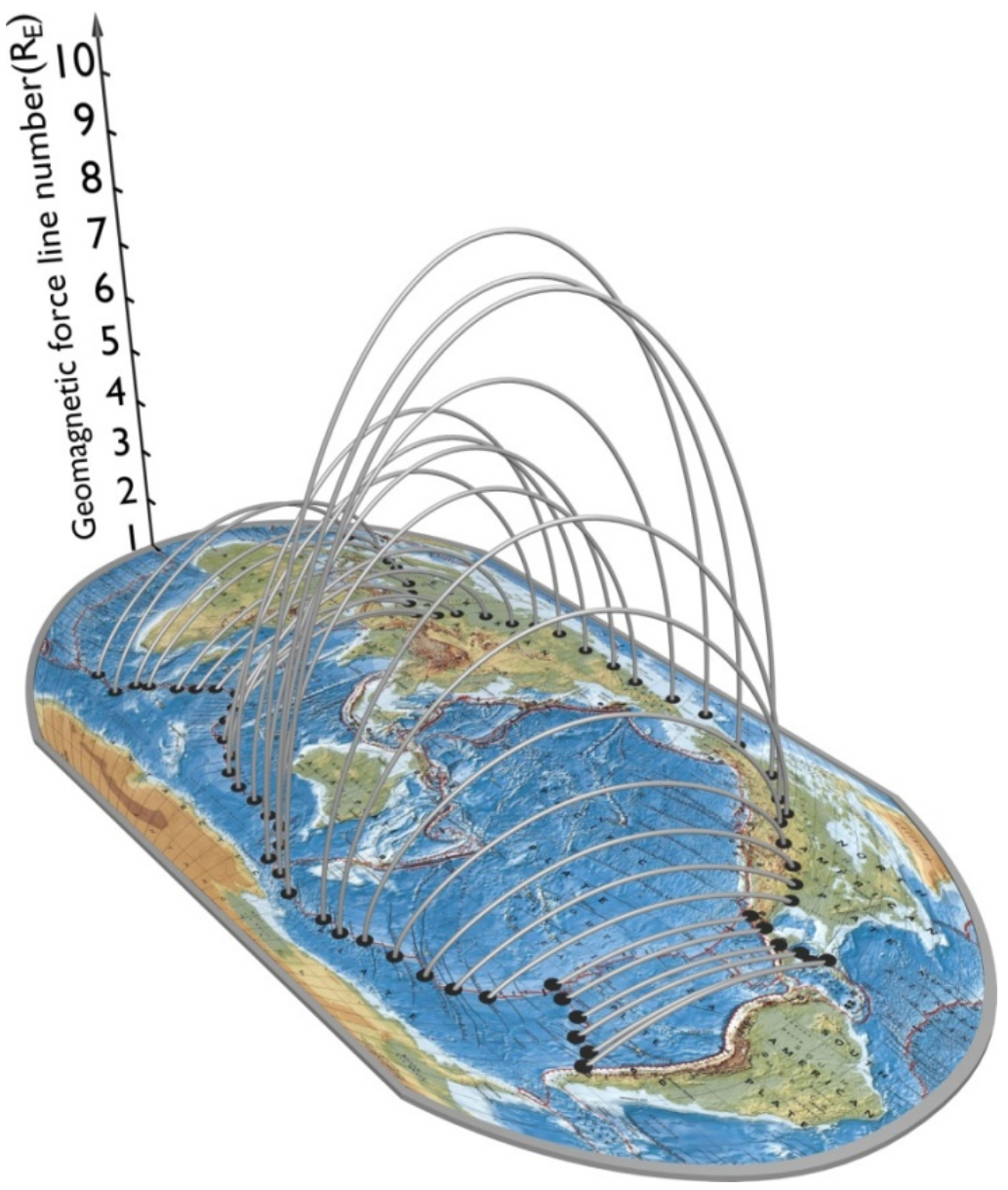

І Рис. 2. Геомагнитные силовые линии, соединяющие магнитосопряженные точки, представленные на рис. 1.

I Fig. 2. Geomagnetic field lines connecting magnetically conjugated sites shown in Fig. 1.

neic.usgs.gov/neis/epic/epic_global.html)) вдоль южной границы литосферной плиты Нацка (479 событий) и северных границ плит Косос и Карибская (569 событий). На этом же рисунке красными кругами показаны магнитосопряженные эпицентры, рассчитанные с использованием программы GEOPACK [Tsyganenko, 2008] и международной справочной модели геомагнитного поля IGRF-10 (http://www.ngdc.noaa.gov/ IAGA/vmod/igrf.html). Достаточно тесное пространственное совпадение между зонами реально зарегистрированных эпицентров и зонами магнитосопряженных (виртуальных) эпицентров подтверждает заключение о магнитной сопряженности южной границы плиты Нацка с северными границами плит Кокос и Карибская. Что касается одновременности возникновения землетрясений в магнитосопряженных зонах, то по данным, представленным на рис. 4 (события с $\mathrm{M} \geq 5.0$ ), таковой не обнаружено. Однако для убедительного ответа на этот вопрос необходимо рассматривать сейсмические толчки и с меньшими магнитудами, так как представленные на рис. 4 эпицентры землетрясений с магнитудой 5.0 и выше далеко не полностью отражают сейсмический режим рассмотренных территорий.

\section{4. ОБСУЖДЕНИЕ И ЗАКЛЮЧЕНИЕ}

В статье обсуждена новая идея [Pulinets, 2009] о том, что появление предвестников землетрясений в характеристиках околоземного космического пространства может быть обусловлено модификацией электрического поля в ГЭЦ электромагнитными возмущениями в литосфере, сопутствующими процессу подготовки землетрясения. Недавно на базе этой идеи было успешно объяснено [Harrison et al., 2010] понижение интенсивности естественного ультранизкочастотного радиоизлучения в верхней ионосфере накануне ощутимых $(\mathrm{M} \geq 5.0)$ коровых землетрясений. Исходя из современной концепции ГЭЦ, в вертикальном токовом контуре, электродинамически связывающем все сферы планеты, роль проводников тока могут выполнять магнитные силовые линии, погруженные в литосферу в магнитосопряженных точках. Считая, что ток, протекающий в конкретном витке цепи в момент его замыкания может стать «триггером» для разрядки накопившегося напряжения в горных породах, авторы предполагают, что зоны структурных нарушений литосферы могут быть магнитосопряженными. Получен- 


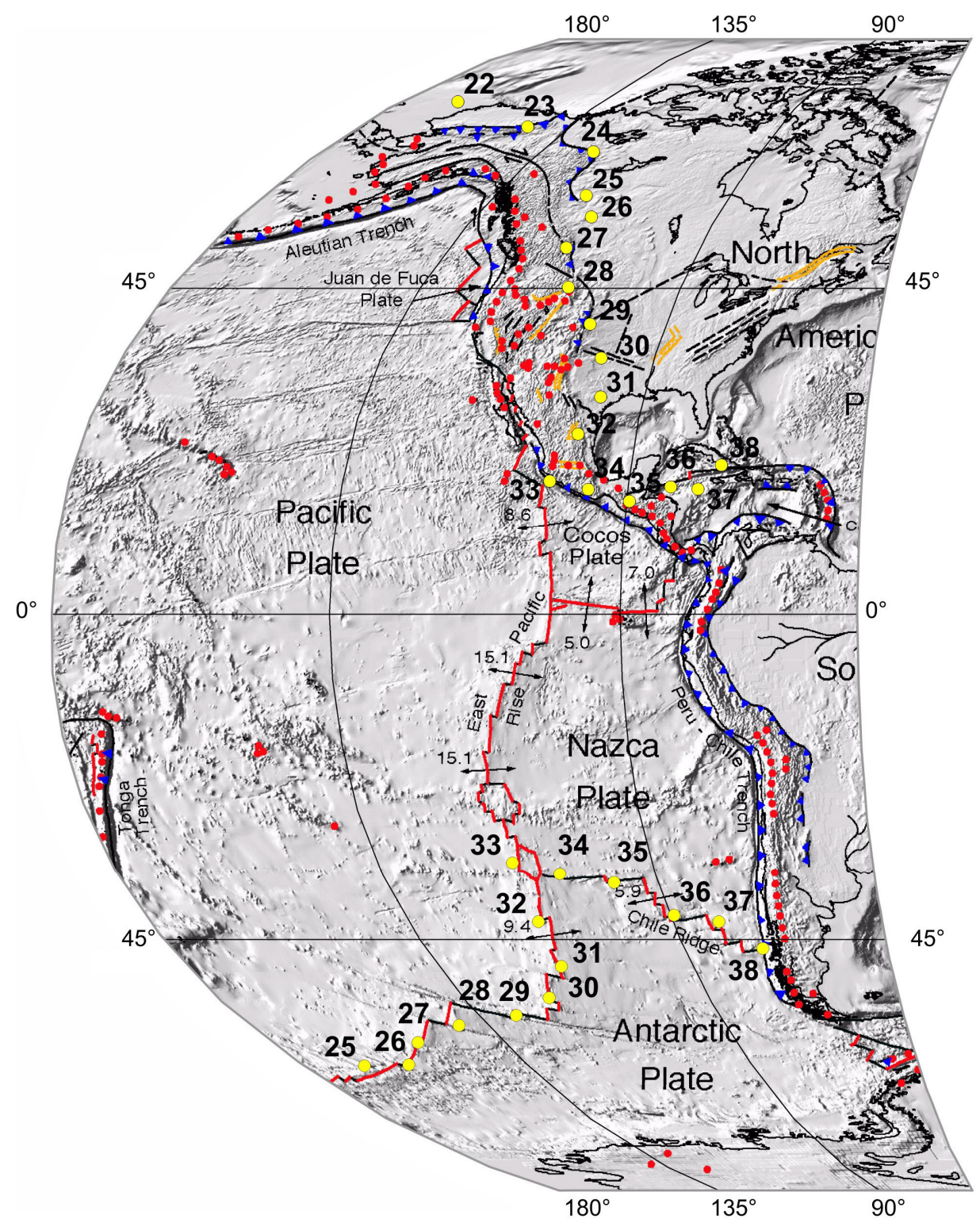

Рис. 3. Фрагмент глобальной цифровой карты тектонической активности Земли (http://denali.gsfc.nasa.gov/dtam).

Желтыми кругами с черными цифрами обозначены магнитосопряженные точки, демонстрирующие наличие «геомагнитной связи» между спрединговой границей Антарктической литосферной плиты в южном полушарии и зоной разломов в районе сочленения Кордильер с Северо-Американской платформой в северном полушарии.

Fig. 3. A fragment of the Digital Tectonic Activity Map (DTAM) (http://denali.gsfc.nasa.gov/dtam).

Yellow circles with black numbers show magnetically conjugated sites that demonstrate a 'geomagnetic connection' between the spreading boundary of the Antarctic lithospheric plate in the southern hemisphere and the fault zone in the area wherein the Cordilleras are conjugated with the North American platform in the northern hemisphere.

ные результаты подтверждают это предположение. Так, срединно-океанические хребты, расположенные в южном полушарии вдоль границы Антарктической литосферной плиты, находятся в магнитной сопряженности с зонами сочленения орогенных и платформенных структур в северном полушарии (см. рис. 1-3).

Вместе с тем карта тектонической активности Земли (см. рис. 1) показывает, что граница Антарктической литосферной плиты расположена, в первом приближении, симметрично орогенному сейсмическо- му поясу в северном полушарии. Это может навести на мысль о чисто механической причине наблюдаемой симметрии, связанной с вращением планеты. Здесь следует отметить, что после работы [Stovas, 1975], в которой предполагается, что изменение ротационного режима Земли приводит к появлению зон повышенной деформации земной коры в районе экватора и «критических параллелей» $\pm 20^{\circ} ; \pm 35^{\circ} ; \pm 60^{\circ}$, было выполнено много работ с целью экспериментальной проверки данной гипотезы. Однако результаты статистического 


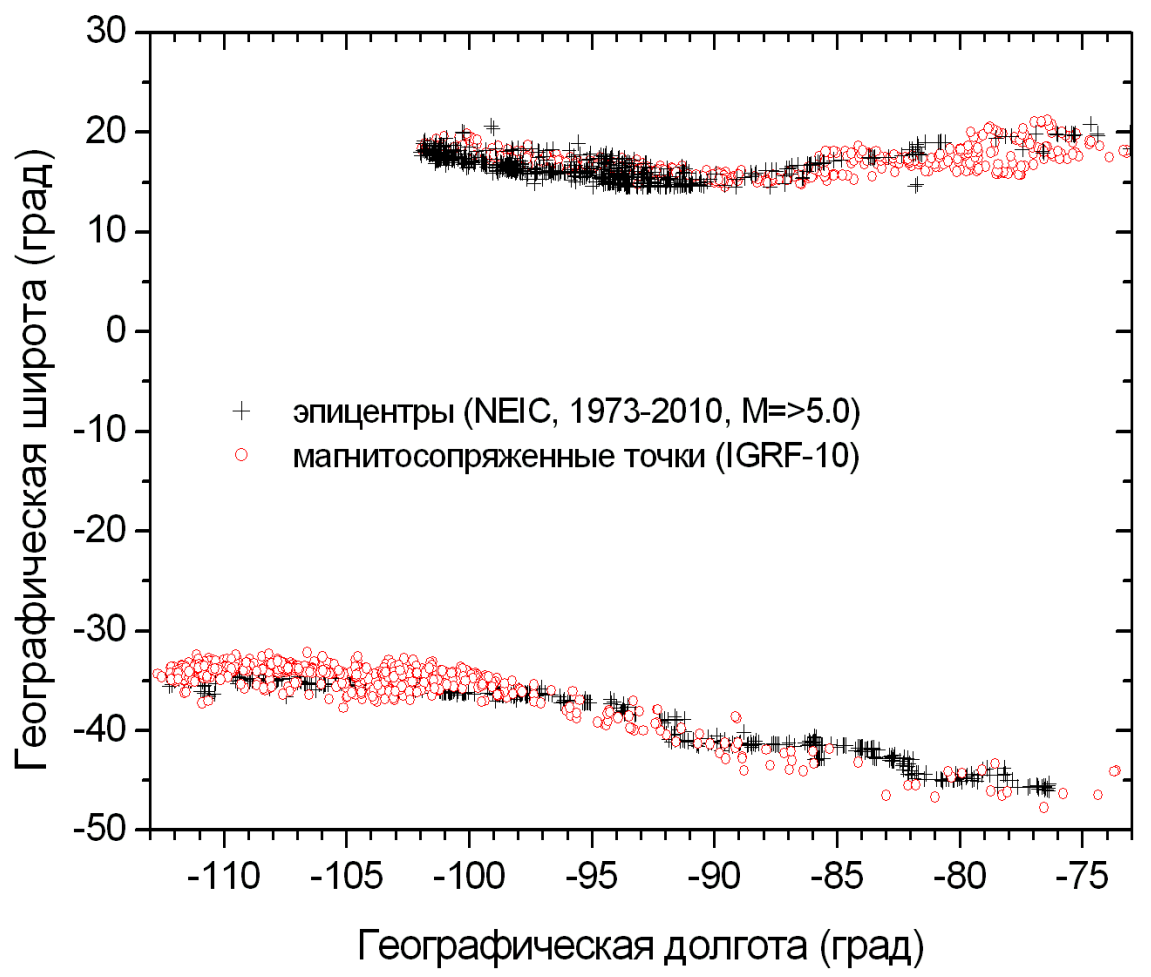

Рис. 4. Черные крестики - эпицентры землетрясений с магнитудой 5.0 и выше.

Fig. 4. Black crosses show epicentres of earthquakes with magnitudes of 5.0 and above.

анализа не показали строгой симметрии в межполушарных пиках сейсмичности. Если в северном полушарии максимум числа землетрясений наблюдается на широте $\sim 40^{\circ} \mathrm{N}$, то в южном полушарии он имеет место на широте $\sim 10^{\circ} \mathrm{S}$. При этом обнаружено [Khachikjan, 2009], что межполушарные пики сейсмичности более четко организованы в зависимости от геомагнитной широты, а не от географической, а еще более четко - в зависимости от угла геомагнитного наклонения. Уже этот факт наводит на мысль, что география сейсмотектонических поясов каким-то образом адаптирована к геометрии главного магнитного поля, и результаты на рисунках 1-3 это мнение укрепляют, хотя физическая причина такой связи пока не ясна.

Магнитосопряженные точки на рисунках 1-3 получены для эпохи 2000 г. Однако магнитное поле Земли постоянно изменяется, следовательно, постоянно будет изменяться номер магнитной силовой линии, выходящей из конкретной точки в южном полушарии, и, соответственно, постоянно будут изменяться координаты магнитосопряженной точки. В настоящее время справочная модель главного магнитного поля разработана для периода 1900-2015 гг. Если, например, рассмотреть на рис. 1 точку «З», которая является точкой тройного сочленения между Антарктической, ЮжноАмериканской и Африканской литосферными плитами и маркирует южную точку Атлантического срединноокеанического хребта, то не трудно оценить, что в
1900 г. магнитная силовая линия, выходящая из точки «3», имела номер $L=2.15$, а в 2015 г. будет иметь номер $L=2.70$. Соответственно, в 1900 г. координаты ее магнитосопряженной точки были $39.51^{\circ} \mathrm{N}, 32.15^{\circ} \mathrm{W}$, а в 2015 г. будут $52.85^{\circ} \mathrm{N}, 28.50^{\circ} \mathrm{W}$. То есть в течение последнего века магнитная силовая линия, выходящая из южной точки Атлантического срединно-океанического хребта, могла входить в северную часть того же самого хребта, смещаясь по широте в северном направлении. Это позволяет предположить, что структурные нарушения земной коры, вытянутые вдоль меридианов, также могут быть следствием функционирования глобальной электрической цепи, конфигурация которой может изменяться в соответствии с вековыми изменениями геометрии геомагнитного поля.

Поскольку все точки земной коры пронизаны магнитными силовыми линиями и каждая из них имеет две магнитосопряженные точки на земной поверхности, возникает закономерный вопрос: «Почему магнитосопряженные сейсмотектонические структуры «привязаны» только к конкретным силовым линиям?» В рамках концепции ГЭЦ эта особенность ожидаема, так как электрический ток в локальном витке цепи, который может быть «триггером» для разрядки накопившегося напряжения в горной породе, может возникнуть только в момент замыкания конкретного витка ГЭЦ. Эффективность замыкания зависит от электрической проводимости, а поскольку не все районы земной 
коры и верхней мантии (где происходят землетрясения) имеют достаточную проводимость, можно ожидать, что только те силовые линии, которым «повезло» выйти из зон разломов земной коры (где проводимость ожидается повышенной) и войти в такие же зоны, могут иметь шанс стать замкнутыми при прочих благоприятных условиях (достаточной в данный момент проводимости атмосферы). Понятно, что эти рассуждения носят спекулятивный характер и требуются практические доказательства замыкания ГЭЦ и в атмосфере, и в твердой земле.

Тесная магнитная сопряженность обнаружена между зонами сейсмичности, приуроченными к южной границе литосферной плиты Нацка и северным границам плит Кокос и Карибская (рис. 4). В то же время «одновременности» в возникновении землетрясений в этих магнитосопряженных зонах не обнаружено, во всяком случае для анализируемых землетрясений с магнитудой 5.0 и выше. Тем не менее для окончательного заключения требуется более глубокий анализ с использованием данных о землетрясениях с меньшими магнитудами.

В целом, результаты статьи следует рассматривать как новый фактологический материал, который при дальнейшем развитии сможет расширить и углубить знания в области взаимосвязи геодинамики, тектоники и геомагнетизма, но еще много дополнительной работы требуется выполнить в этом направлении.

\section{5. БЛАГОДАРНОСТИ}

Авторы глубоко признательны профессору С.И. Шерману за внимание к данным результатам, первоначально представленным на одной из секций 33-й Генеральной ассамблеи Европейской сейсмологической комиссии (Москва, август 2012 г.), и предложение рассмотреть возможность их опубликования в журнале. Авторы глубоко благодарны рецензентам работы за проведенный анализ и ценные замечания, которые несомненно способствовали улучшению статьи.

\section{6. ЛИТЕРАТУРА}

Afonin V.V., Molchanov O.A., Kodama T., Hayakawa M., Akentieva O.A., 1999. Ionospheric response to long seismic influence: Search for reliable result from satellite observations. In: Hayakawa M. (Ed.), Atmospheric and Ionospheric Electromagnetic Phenomena Associated with Earthquakes. Terra Scientific Publishing Company, p. 597-618.

Bering E.A., Few A.A., Benbrook J.R., 1998. The Global Electric Circuit. Physics Today 51 (10), 24-30. http://dx.doi.org/ 10.1063/1.882422.

Harrison R.G., 2004. The global atmospheric electrical circuit and climate. Surveys in Geophysics 25 (5-6), 441-448. http:// dx.doi.org/10.1007/s10712-004-5439-8.

Harrison R.G., Aplin K., Rycroft V., 2010. Atmospheric electricity coupling between earthquake regions and the ionosphere. Journal of Atmospheric and Solar-Terrestrial Physics 72 (5-6), 376-381. http://dx.doi.org/10.1016/j.jastp.2009.12.004.

Khachikjan G., 2009. Spatial scale earthquake statistics in geomagnetic coordinates. In: Procedings of International earthquake symposium. Kocaeli, August 17-19, 2009. p. 407-413. Available from: http://kocaeli2009.kocaeli.edu.tr (last accessed 13.05.2013.).

Makarova L.N., Shirochkov A.V., 1998. A new approach to the global electric circuit conception. Available from: http://www.sgo.fi/SPECIAL/Contributions/Makarova.pdf (last accessed 13.05.2013.).

National Research Council Commission on Physical Sciences, Mathematics, and Applications. The Earth's Electrical Environment. National Academies Press, Washington D.C., 1986. Available from: http://books.nap.edu/books/0309036801/ html/211.html\#pagetop (last accessed 13.05.2013.).

Němec F., Santolı'k O., Parrot M., 2009. Decrease of intensity of ELF/VLF waves observed in the upper ionosphere close to earthquakes: A statistical study. Journal of Geophysical Research: Space Physics 114 (A4), A04303. http://dx.doi.org/ 10.1029/2008JA013972.

Ohtani S., Fujii R., Hesse M., Lysak R., 2000. Magnetospheric Currents Systems. Part of the Geophysical monograph series 118, $401 \mathrm{p}$.

Pulinets S.A., 2009. Physical mechanism of the vertical electric field generation over active tectonic faults. Advances in Space Research 44 (6), 767-773. http://dx.doi.org/10.1016/j.asr.2009.04.038.

Pulinets S.A., Biagi P., Tramutoli V., Legen'ka A.D., Depuev V.Kh., 2007. Irpinia earthquake 23 November 1980 - Lesson from Nature reviled by joint data analysis. Annales of Geophysics 50 (1), 61-78. http://dx.doi.org/10.4401/ag-3087.

Pulinets S.A, Boyarchuk K.A., 2004. Ionospheric Precursors of Earthquakes. Berlin, New York: Springer. 316 p.

Ruzhin Yu.Ya., Larkina V.A., Depueva A.Kh., 1998. Earthquake precursors in magnetically conjugated ionosphere regions. Advances in Space Research 21 (3), 525-528. http://dx.doi.org/10.1016/S0273-1177(97)00892-2.

Rycroft M.J., Israelsson S., Price C., 2000. The global atmospheric electric circuit, solar activity and climate change. Journal of Atmospheric and Solar-Terrestrial Physics 62 (17-18), 1563-1576. http://dx.doi.org/10.1016/S1364-6826(00)00112-7. 
Stovas M.V., 1975. The selected works. Nedra, Moscow, 155 р. (in Russian) [Стовас М.В. Избранные труды. М.: Недра, 1975. 155 c.].

Tsyganenko N.A., 2008. Geopack: A Set of Fortran Subroutines for Computations of the Geomagnetic Field in the Earth's Magnetosphere. Available from: http://geo.phys.spbu.ru/ tsyganenko/Geopack-2008.html (last accessed 13.05.2013.).

Wilson C.T.R., 1921. Investigations on lightning discharges and on the electric field of thunderstorms. Philosophical Transactions of the Royal Society A 221 (582-593), 73-115. http://dx.doi.org/10.1098/rsta.1921.0003
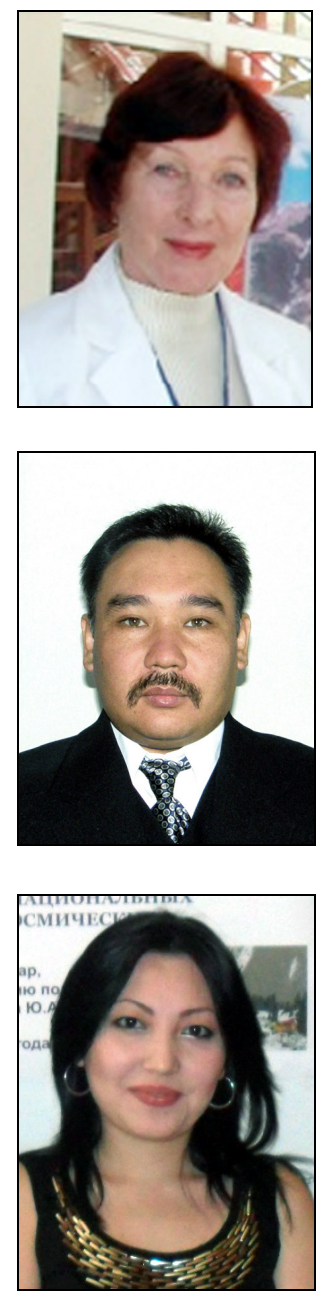

Хачикян Галина Яковлевна, докт. физ.-мат. наук, г.н.с.

ДТОО Институт ионосферы АО «Национальный центр космических исследований и технологий», Национальное космическое агентство Республики Казахстан 050020, Республика Казахстан, Алматы, Каменское плато

$\triangle$ e-mail: galina.khachikyan@gmail.com

Khachikyan, Galina Ya., Doctor of Physics and Mathematics, Chief Researcher

LLC Institute of Ionosphere JSC National Center for Space Research and Technology,

National Space Agency of Kazakhstan, Almaty, Republic of Kazakhstan

Kamenskoye Plato, Almaty 050020, Republic of Kazakhstan

\ e-mail: galina.khachikyan@gmail.com

Жакупов Нурлан Самратович, н.с.

ТОО Институт сейсмологии, АО «Национальный Научно-Технологический Холдинг “ПАРАСАТ”»,

Министерства образования и науки Республики Казахстан

050060, Алматы, ул. Аль-Фараби, 75А, Республика Казахстан

e-mail: NZ@mail.ru

Zhakupov, Nurlan S., Researcher

LLC Institute of Seismology JSC National Science and Technology Holding PARASAT,

Ministry of Education and Science of Kazakhstan

Al-Farabi, 75A, Almaty 050060, Republic of Kazakhstan

e-mail: NZ@mail.ru

Кадырханова Назигуль Жунусхановна, м.н.с.

ТОО Институт сейсмологии, АО «Национальный Научно-Технологический Холдинг “ПАРАСАТ”», Министерства образования и науки Республики Казахстан

050060, Алматы, ул. Аль-Фараби, 75А, Республика Казахстан

e-mail: NZ@mail.ru

Kadyrkhanova, Nazigul' Zh., Junior Researcher

LLC Institute of Seismology JSC National Science and Technology Holding PARASAT,

Ministry of Education and Science of Kazakhstan

Al-Farabi, 75A, Almaty 050060, Republic of Kazakhstan

e-mail: NZ@mail.ru 